\title{
DETERMINAÇÃO DE TRICOTECENOS EM CERVEJA E AVALIAÇÃO DE INCIDÊNCIA NO PRODUTO COMERCIALIZADO NO RIO GRANDE DO SUL ${ }^{1}$
}

\author{
Jaqueline GARDA ${ }^{2}$, Rejane Martins MACEDO ${ }^{3}$, Eliana BADIALE-FURLONG ${ }^{4, *}$
}

\begin{abstract}
RESUMO
Este trabalho adaptou um método e avaliou os seus indicadores de mérito para determinação de tricotecenos, desoxinivalenol (DON) e toxina T-2, em cervejas comercializadas na região Sul do Rio Grande do Sul, empregando cromatografia gasosa. As adaptações foram realizadas na etapa de extração, purificação, derivação e condições cromatográficas usando amostras de cerveja artificialmente contaminadas, avaliando a adequação do procedimento pela recuperação obtida. Foram estudados os solventes acetonitrila, metanol e cloreto de metileno puro ou em misturas para a etapa de extração. A purificação do extrato foi realizada empregando ou não minicoluna de carvão:alumina:celite (7:5:3). Para a derivação testou-se basicidade do meio (bicarbonato de sódio, piridina), agente acilante (TFAA e HFBI), tempo (30 e 60 minutos) e temperatura $\left(60\right.$ e $\left.80^{\circ} \mathrm{C}\right)$. Foram otimizadas as condições cromatográficas em cromatógrafo gasoso equipado com injetor split/splitless e detector de ionização de chama. A melhor recuperação foi obtida quando se empregou partição líquido-líquido com cloreto de metileno, seguida da limpeza em minicoluna e derivação com TFAA e piridina a $60^{\circ} \mathrm{C}$ durante 60 minutos. A recuperação média foi de 83 e $103 \%$ para DON e toxina T-2 respectivamente, para niveis de adição entre 50 e 200 ng/mL. O coeficiente de variação assumiu valores de $2 \%$ e $4 \%$ e limite de detecção de 21 e $60 \mathrm{ng} / \mathrm{mL}$. A aplicabilidade do método foi testada em um levantamento realizado em 72 amostras de cervejas. Destas 9,7\% estavam contaminadas, sendo 5,3\% com DON (50 a 336ng/mL) e $4,5 \%$ com toxina T-2 (114 a $249 \mathrm{ng} / \mathrm{mL}$ ).

Palavras-chave: tricotecenos; cervejas; desoxinivalenol; toxina T-2; cromatografia gasosa.
\end{abstract}

\section{SUMMARY}

DETERMINATION OF TRICHOTHECENES IN BEER AND EVALUATION OF OCCURENCE IN THE PRODUCT COMMERCIALIZED IN RIO GRANDE DO SUL. The present work adapted and evaluated a trichothecenes determination, DON and the T-2 toxin and conduted a survey of the product commercialized in Rio Grande do Sul in beer commercialized in Rio Grande do Sul State by gas chromatography. It studied extraction, purification, derivatization and chromatographic conditions using artificially contaminated samples. Acetonitrile, methylene chloride and methanol pure or in misture were tested for the extraction step. The extract was purified using a carbon:alumina:celite minicolumn (7:5:3). For derivatization, the following conditions were tested: the basicity of the medium (sodioum bicarbonate, pyridine), the derivatizing agent (TFAA and $\mathrm{HFBI}$ ), reaction time (30 and 60 minutes) and temperature (60 and $80^{\circ} \mathrm{C}$ ). The chromatographic conditions were optimized in a gas chromatograph, with a split/splitless injector and an ionization flame detector. The highest recovery was obtained when liquid-liquid partition was carried out with methylene chloride, followed by cleaning in a minicolumn and derivatization with TFAA and pyridine at a temperature of $60^{\circ} \mathrm{C}$ for 60 minutes. The average recovery for DON and the T-2 toxin were 83 and 103\%, the coefficient variation 1.6 to $4 \%$ and the detection limit of 21 and 60 ng/mL, respectively. The applicability of the method was tested in a survey carried out in 72 beer samples, $9.7 \%$ of which were contaminated $5.3 \%$ with DON (50 to $336 \mathrm{ng} / \mathrm{mL}$ ) and $4.5 \%$ with the T-2 toxin (114 to $249 \mathrm{ng} / \mathrm{mL}$ ).

Keywords: trichothecenes; beer; deoxynivalenol; T-2 toxin; gas chromatographic.

\section{1 - INTRODUÇÃO}

Os tricotecenos são micotoxinas constituídas por anéis tricotecanos que apresentam uma ligação dupla entre os carbonos 9 e 10 e um grupamento epóxido nas posições 12 e 13 da estrutura. A literatura relata 190 estruturas de tricotecenos que tem sido identificadas [12]. Os átomos de carbono ligados a um grupo hidroxila, acetil ou cetônico podem sofrer reações químicas características destes grupamentos. Estas reações são principalmente realizadas para estudo da estrutura e detecção destes compostos em alimentos e rações [1, $3,27,31]$.

As micotoxinas deste grupo são produzidas por diversos gêneros de fungos: Fusarium, Trichoderma,

\footnotetext{
Recebido para publicação em 26/08/2003. Aceito para publicação em 04/08/2004 (001201).

2. Departamento de Química, Engenharia de Alimentos, Fundação Universidade Federal do Rio Grande (FURG).

3. Departamento de Química, Engenharia Química, FURG.

4. Departamento de Química, Engenharia de Alimentos, FURG.

* A quem a correspondência deve ser enviada.
}

Myrothecium, Stachybotrys, Cylindrocarpon, e Trichothecium, do qual o nome tricoteceno foi derivado. Apesar do grande número destes compostos na natureza, somente pequena quantidade, menos de 10, têm sido detectados a partir de contaminação natural em alimentos, tais como desoxinivalenol (DON), nivalenol, toxina T-2, diacetoxiscirpenol e toxina HT-2 [11, 17, 20].

Os tricotecenos inibem a sintese de proteínas, de DNA e RNA e acarretam efeitos imunossupressores e hemorrágicos [10,12]. O efeito tóxico dos tricotecenos se deve principalmente ao anel epóxido, pois sua destruição resulta em perda total da toxicidade. No entanto, há evidências que indicam a influência dos grupamentos substituintes e da ligação dupla entre o carbono 9-10 nesta característica [13, 27, 31].

A cromatografia gasosa é a técnica mais utilizada na separação, identificação e quantificação de misturas de tricotecenos, embora também sejam utilizadas cromatografia de camada delgada, cromatografia líquida de alta eficiência e cromatografia de fluído supercrítico [18]. Além da etapa de extração, um ponto crítico na determinação de tricotecenos, por cromatografia gasosa, vem a ser a derivação que deve ser efetuada 
previamente ao processo cromatográfico. Estão disponiveis diversos sistemas para derivação como anidrido trifluoro acético (TFAA), heptafluorobutirilimidazol (HFBI), pentafluorobutirilimidazol PFBI), trimitilsilil (TMS), bistrimetilsililacetamida (BSA), hexametildisilazano (HMDS) e trimetilsililimidazol (TMSIM) [7, 9, 31]. O emprego destes reagentes de derivação reduz a polaridade dos grupamentos livres, aumenta a pressão de vapor dos compostos, possibilitando a separação de substâncias muito semelhantes entre si no estado natural e introduz grupos que tornam o composto adequado ao sistema de detecção empregado [1, 11].

Dentre as amostras de cereais mais estudadas, as freqüentemente mencionadas como contaminadas são a cevada e o trigo [14, 29]. Os níveis de contaminação variam de acordo com a micotoxina estudada, sendo que os tricotecenos são conhecidos por resistir aos principais processamentos a que estes grãos são submetidos [21]. Dentre os produtos que podem ser contaminados por tricotecenos estão as bebidas alcoólicas produzidas a partir de grãos cereais contaminados.

A cerveja, por exemplo, é um caso de risco de contaminação de tricotecenos pelo uso de cevada e outros cereais como matéria-prima. No caso do Brasil, a preocupação com esta bebida decorre do aumento do seu consumo, em média 50L/pessoa/ano, e do fato que os cereais utilizados para a produção são provenientes de países onde tradicionalmente estas toxinas são detectadas [3, 25].

Estas considerações nortearam este trabalho que teve como objetivo adaptar uma metodologia para determinação de tricotecenos, DON e toxina T-2, em cervejas por cromatografia gasosa. O ponto de partida foram os procedimentos já empregados no Laboratório de Micotoxinas da Fundação Universidade Federal do Rio Grande para determinação destas micotoxinas em trigo, cevada e arroz, empregando cromatografia gasosa e de camada delgada. As adaptações introduzidas foram avaliadas através dos níveis de recuperação em amostras artificialmente contaminadas.

\section{2 - MATERIAIS E MÉTODOS}

\section{1 - Padrões de tricotecenos}

Os padrões das toxinas DON e toxinas T-2 foram adquiridos da Sigma Chemical Company (E.U.A.). Para o preparo das soluções estoques, as toxinas foram dissolvidas em benzeno:acetonitrila (95:5) resultando em uma concentração de $100 \mu \mathrm{g} / \mathrm{mL}$ [26]. As soluções de trabalho consistiram na diluição das soluções estoque para a concentração de $50 \mu \mathrm{g} / \mathrm{mL}$. A determinação das concentrações das soluções foram realizadas pela relação $\mathrm{p} / \mathrm{v}$ e pelo procedimento descrito por BENNETT \& SHOTWELL [4] utilizando a absortividade molar dos padrões 219 e 203, respectivamente para DON e toxina T-2.

\section{2 - Amostras}

Amostras de cervejas foram coletadas em estabelecimentos comerciais na cidade de Rio Grande (RS), sendo escolhidas quatro marcas mais freqüentemente consumidas segundo grupos de consumidores entrevistados na comunidade universitária e em distribuidores comerciais. Foram coletadas na amostragem os três tipos de embalagens comercializadas (lata $250 \mathrm{~mL}$, garrafas $800 \mathrm{~mL}$, longneck $350 \mathrm{~mL}$ ). Neste momento foram formados lotes brutos de $1 \%$ do produto disponível na prateleira dos estabelecimentos comerciais de maneira aleatória para cada tipo de embalagem. Destes foram tomados $1 \%$ para comporem os lotes de laboratório. As embalagens de mesma marca foram abertas, e transferidas para um recipiente, homogeneizadas, degaseificadas por agitação em banho ultrassônico e a partir desta foram retiradas às alíquotas analíticas.

O levantamento foi composto de 72 amostras, com diferentes embalagens, das 4 marcas mais consumidas, coletadas em três diferentes datas entre maio e setembro de 2001. As determinações foram realizadas em duplicata.

Para padronização da metodologia foi empregada uma das marcas selecionadas para amostragem preparada da mesma forma e contaminada com DON e toxina T-2 em niveis variando de 50 a $200 \mathrm{ng} / \mathrm{mL}$.

\section{3 - Padronização de procedimentos para detecção e quantificação em cromatografia gasosa}

Primeiramente, o método cromatográfico descrito por NUNES [15] foi testado para obter os tempos de retenção das toxinas estudadas, DON e toxina T-2. Este método consiste em derivar o padrão usando $300 \mu \mathrm{L}$ de TFAA, tendo como catalisador bicarbonato de sódio. Entretanto, foi necessário otimizar as condições de derivação, pois neste método os padrões apresentaram pequenas áreas relativas, havendo possibilidade de derivação incompleta.

Desta forma, as condições de derivação foram avaliadas variando a basicidade do meio, agente acilante, tempo e temperatura de derivação, como apresentado nas Tabelas 1 e 2 visando prepará-los para detecção e quantificação em cromatografia gasosa.

Esta foi realizada em um cromatógrafo gasoso Varian 3400 equipado com injetor split/splitless e detector de ionização de chama, coluna de $0,32 \mathrm{~mm}$ de diâmetro interno, $30 \mathrm{~m}$ de comprimento e fase estacionária de polietilenoglicol (coluna DB-FFAP J\&W). O equipamento foi monitorado pelo software Star Chromatography Workstation, versão 4.51, marca Varian.

As condições cromatográficas estudadas para a injeção foram o tempo de abertura da válvula $(0,25 ; 0,5$ e 0,75 minuto), diferentes programações de temperatura para a coluna, mantendo a temperatura do detector em $300^{\circ} \mathrm{C}$ para todas as condições testadas de programação. Os resultados foram avaliados pelo perfil dos cromatogramas e áreas relativas dos padrões nos seus tempos de retenção característicos usando como padrão interno ácido araquídico.

Para confirmação foram realizadas co-cromatografia e derivações químicas segundo BADIALE-FURLONG 
\& SOARES [2], empregando redução com boridreto de lítio e acilação com anidrido acético para DON e toxina T-2 respectivamente, seguido pela derivação usual antes da separação cromatográfica.

TABELA 1. Condições de derivação usando bicarbonato de sódio.

\begin{tabular}{cccc}
\hline Testes & Bicarbonato de sódio $(\mathrm{mg})$ & TFAA $(\mu \mathrm{L})$ & Temperatura $\left({ }^{\circ} \mathrm{C}\right)$ \\
\hline 1 & 15 & 200 & 60 \\
2 & 15 & 300 & 60 \\
3 & 15 & 100 & 60 \\
4 & 20 & 200 & 60 \\
5 & 20 & 300 & 60 \\
6 & 20 & 100 & 60 \\
7 & 30 & 200 & 60 \\
8 & 30 & 300 & 60 \\
9 & 30 & 100 & 60 \\
10 & 15 & 300 & 80 \\
\hline
\end{tabular}

TABELA 2. Condições de derivação para tricotecenos.

\begin{tabular}{cccc}
\hline Meio básico & Agente acilante & Tempo (minutos) & Temperatura $\left({ }^{\circ} \mathrm{C}\right)$ \\
\hline $\mathrm{NaHCO}_{3}$ & TFAA & 60 & $60 / 80$ \\
Piridina $(1 \mathrm{~mL})$ & TFAA $(300 \mu \mathrm{L})$ & 60 & $60 / 80$ \\
Piridina $(1 \mathrm{~mL})$ & HFBI $(50 \mu \mathrm{L})$ & 60 & $60 / 80$ \\
- & TFAA $(300 \mu \mathrm{L})$ & 60 & $60 / 80$ \\
- & HFBI $(50 \mu \mathrm{L})$ & 60 & $60 / 80$ \\
\hline
\end{tabular}

\section{4 - Extração}

A avaliação da etapa de extração foi realizada tomando 4 alíquotas de $50 \mathrm{~mL}$ de cerveja artificialmente contaminada, cada uma com um nível de contaminação 50 a 200ng/mL de cada toxina. As condições de extração empregaram:

- Sistema 1: Metanol: cloreto de potássio: amostra (9:1:1,66), precipitação com sulfato de amônia e celite e três partições sucessivas com porções de $10 \mathrm{~mL}$ de cloreto de metileno.

- Sistema 2: Acetonitrila: água: amostra $(9: 1: 1,66)$ e partição com cloreto de metileno.

- Sistema 3: Metanol: acetato de etila: amostra $(4,5: 1,5: 1)$ e três partições sucessivas com porções de $10 \mathrm{~mL}$ de cloreto de metileno.

- Sistema 4: Metanol: acetato de etila: amostra (4,2: 1,8: 1) e três partições sucessivas com porções de $10 \mathrm{~mL}$ de cloreto de metileno.

- Sistema 5: Amostra e três partições sucessivas com porções de $10 \mathrm{~mL}$ de cloreto de metileno.

A limpeza de todos os extratos foi realizada empregando minicoluna preparada com carvão ativo:alumina:celite (7: 5: 3), conforme BADIALE-FURLONG \& SOARES [2]. Foram avaliados os efeitos de eluição com volumes de 20, 30 e 40mL de clorofórmio e cloreto de metileno.

\section{5 - Avaliação de exatidão, precisão, limite de quan-} tificação e linearidade do método adaptado

Após o estabelecimento das condições de extração, limpeza, derivação e detecção das toxinas em amostras de cerveja contaminadas artificialmente em quatro niveis 50, 100, 150 e 200ng/mL, armazenadas à temperatura ambiente por 24 horas antes da extração, foram testadas as figuras de mérito:

- exatidão, indicada pela diferença entre o valor obtido e o valor real do analito na matriz, expressos como porcentagem de recuperação;

- precisão avaliada como coeficiente de variação de média de quatro repetições dos níveis contaminados artificialmente;

- linearidade testada a partir de derivação de soluções de DON e toxina T-2, contendo de 0,875 a $12,250 \mu \mathrm{g}$, injetadas no cromatógrafo e estabelecimento de curvas padrão considerando concentrações e áreas relativas dos padrões;

- os limites de detecção e quantificação, foram determinados pela diluição de padrões e de amostras contaminadas a concentrações que gerassem um sinal do detector duas vezes superior ao desvio padrão das áreas relativas no tempo de retenção das toxinas quando se injetava um branco de derivação [5].

\section{3 - RESULTADOS}

\section{1 - Estabelecimento das condições de derivação e detecção em cromatografia gasosa}

A literatura menciona freqüentemente o emprego de heptafluorobutirilimidazol (HFBI) ou pentafluorobutirilimidazol (PFBI) como reagentes derivatizantes para determinação de tricotecenos por cromatografia gasosa. No entanto, segundo SCOTT [22], os derivados de HFBI apresentam boas características para serem detectados por sistemas que empreguem detectores de captura eletrônica ou de massa, porém por gerar maiores quantidades de íons negativos poderiam levar a maior dificuldade para geração de sinais em detectores de ionização de chama.

Um outro problema com os reagentes mencionados, no Brasil, é o custo e a disponibilidade dos mesmos no comércio de reagentes químicos. Além disso, os equipamentos mais versáteis e acessiveis aos laboratórios nacionais são os que empregam detectores de ionização de chama. Considerando estes aspectos NUNES [15] e OLIVEIRA [16], realizaram estudos em cromatógrafos gasosos com detectores de ionização de chama para avaliar a possibilidade de empregar o anidrido trifluoroacético (TFAA), em meio alcalino como reagente derivatizante. A primeira, observou experimentalmente menores áreas, quando empregou o HFBI comparativamente a este. Assim, o reagente derivatizante escolhido para se iniciar a etapa de volatilização dos tricotecenos DON e toxina T-2 neste trabalho foi o 
TFAA. Para otimizar a estimativa dos tempos de retenção e a quantificação dos padrões foi empregado um padrão interno (ácido araquídico) e os resultados mostraram tempos de retenção de 5,2 minutos para DON e 12,54 minutos para toxina T-2.

Empregando o TFAA como derivatizante um ponto a ser estudado é o tipo de catalisador básico a ser empregado. Primeiramente, foram avaliadas as quantidades de bicarbonato de sódio a ser utilizado, pois o excesso dele poderia ocasionar reversão da reação [19], também foram estudados os efeitos dos tempos e temperaturas para a acetilação. Os resultados das diferentes condições empregadas foram avaliados pela área relativa dos padrões, cujas diferenças foram estimadas pela variância e teste de Tukey.

A melhor resposta para condições de derivação para as duas toxinas simultaneamente foi observada, quando se empregou $15 \mathrm{mg}$ de bicarbonato de sódio e $300 \mu \mathrm{L}$ de TFAA, com um tempo de derivação de 60 minutos a uma temperatura de $60^{\circ} \mathrm{C}$, ou seja, o segundo ensaio efetuado, como mostra a Figura 1.

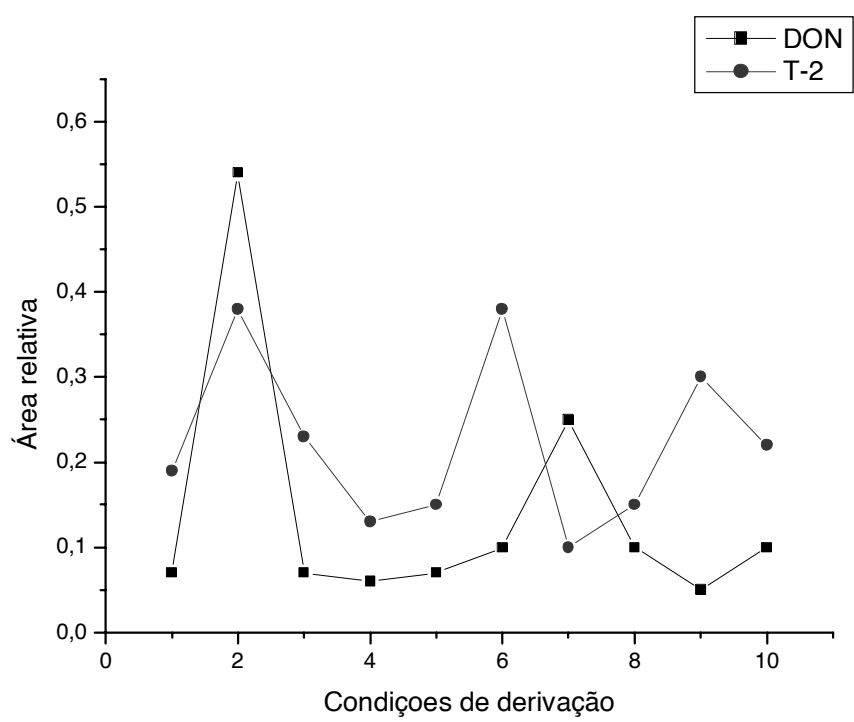

FIGURA 1. Gráfico das interações obtidas pelo Teste de Tukey.

A comparação da derivação com TFAA utilizando bicarbonato de sódio e piridina, mostrou que o último catalisador empregado foi o melhor. Tal observação, também foi relatada por GILBERT et al. [7], SCOTT [22], KIENTZ \& VERWEIJ [9]. Não foram observadas diferenças significativas nas áreas relativas obtidas quando foram avaliados o tempo e temperatura de derivação para o catalisador piridina. A escolha de 60 minutos a uma temperatura menor foi visando minimizar a degradação dos produtos derivados [9, 22].

De acordo com GILBERT et al. [7] e SCOTT [22], o uso do catalisador piridina também favorece o aumento da degradação, mas tem como vantagem gerar áreas maiores e cromatogramas mais limpos, comparativamente aos outros catalisadores, porém o trabalho experimental mostrou que a determinação cromatográfi- ca deve ser realizada logo após a reação, pois maiores áreas foram observadas, quando a cromatografia se realizava até 72 horas após derivação.

Para finalizar a padronização do procedimento a ser adotado para detecção e quantificação dos tricotecenos, foi realizado um estudo das condições cromatográficas adotando como critério de adequacidade a resolução dos compostos, o tempo de análise e o menor número de interferentes na região dos tempos de retenção característico do contaminante esperado. As condições cromatográficas que mais satisfizeram estes critérios foram: temperatura do injetor de $250^{\circ} \mathrm{C}$, abertura da válvula "splitless" há 0,75 minuto, temperatura do detector $300^{\circ} \mathrm{C}$, atenuação $16 \times 10^{11}$. A programação da coluna foi: $100^{\circ} \mathrm{C} / 2$ minutos, aumentando $50^{\circ} \mathrm{C} / \mathrm{minu}-$ tos até $220^{\circ} \mathrm{C}$, permanecendo por 1 minuto, em seguida aumentando $15^{\circ} \mathrm{C} /$ minutos até $235^{\circ} \mathrm{C}$, permanecendo por 30 minutos.

\section{2 - Estabelecimento das condições de extração e limpeza das toxinas}

Os testes de eficiência de extração empregando diferentes solventes foram avaliados pelos teores de recuperação de DON e toxina T-2 adicionados artificialmente em amostras de cervejas. Os percentuais de recuperação obtidos com os diferentes sistemas estão apresentados na Tabela 3.

TABELA 3. Recuperação de DON e toxina T-2 empregando diferentes sistemas de extração.

\begin{tabular}{ccc}
\hline Testes de extração & $\begin{array}{c}\text { Recuperação de DON } \\
(\%)\end{array}$ & $\begin{array}{c}\text { Recuperação de T-2 } \\
(\%)\end{array}$ \\
\hline 1 & - & 75 \\
2 & 50 & 40 \\
3 & - & 70 \\
4 & 20 & 70 \\
5 & 83 & 103 \\
\hline
\end{tabular}

$1,2,3,4,5$ : sistema de extração em amostras artificialmente contaminadas de 50 a $200 \mathrm{ng} / \mathrm{mL}$ descritos no item 2.4

O sistema 1 que emprega metanol $/ \mathrm{KCl}$ vem sendo utilizado por outros autores para extração simultânea de tricotecenos do grupo A e B e mesmo de outras micotoxinas em trigo, malte, e arroz [2, 3, 13, 15, 28]. Para a cerveja observou-se que este sistema não foi eficiente para DON, mesmo apresentando uma recuperação de $75 \%$ para a toxina T-2.

O sistema 2, que emprega a acetonitrila, foi escolhido considerando sua polaridade intermediária conforme TANAKA et al. [30] e SCOTT [25]. Os cromatogramas mostravam a presença de muitos interferentes com comportamento semelhante ao DON, o que poderia ser a causa de se obter uma recuperação de $50 \%$ desta toxina da amostra contaminada. Outros testes que empregaram solventes de menor polaridade, como os dos experimentos 3 e 4, também não demonstraram sucesso para esta toxina. Em geral, pode-se observar que desta matriz a toxina T-2 pode ser mais facilmente ex- 
traída, possivelmente por sua menor polaridade em relação ao DON.

A escolha de diclorometano em lugar de clorofórmio como descrito por BADIALE-FURLONG [1] e SOARES [28], acarretou melhores valores de recuperação obtidos para as duas toxinas simultaneamente, 83 e 103\% para DON e toxina T-2. Tal característica já tinha sido observada por BARAJ [3] quando se tratava de amostras contaminadas de malte. Esta situação poderia ser atribuída à polaridade do solvente mais adequada para a separação das toxinas da matriz aquosa das amostras.

\section{3 - Metodologia proposta}

Após os testes descritos acima, o método proposto para determinação de DON e toxina T-2 consistiu em: homogeneizar $50 \mathrm{~mL}$ de amostra, $50 \mathrm{~mL}$ de água destilada em funil de separação seguida de três partições com $10 \mathrm{~mL}$ de cloreto de metileno. As três alíquotas da partição foram reunidas, agitadas em banho ultrassônico e em seguida separadas em três porções (duas de $10 \mathrm{~mL}$ - quantificação e confirmação e o restante - triagem) e evaporadas em banho-maria a $50^{\circ} \mathrm{C}$ sob atmosfera de nitrogênio.

Para limpeza do extrato foi empregado minicoluna de carvão ativo:celite:alumina (7:5:3), eluindo com 40mL de cloreto de metileno. No resíduo seco foi efetuada a derivação com $1 \mathrm{~mL}$ de $1,5 \mathrm{mg} / \mathrm{mL}$ piridina em tolueno: acetontrila (95:5) e $300 \mu \mathrm{L}$ de anidrido trifluoroacético (TFAA), tratados a $60^{\circ} \mathrm{C}$ durante 60 minutos. Este extrato foi seco e foram adicionados $700 \mu \mathrm{L}$ de tolueno e $2 \mathrm{~mL}$ de tampão fosfato $0,1 \mathrm{M} \mathrm{pH} \mathrm{7,} \mathrm{agitados} \mathrm{e} \mathrm{congelados}$ para melhor separação das fases. Da fase orgânica foram retirados $400 \mu \mathrm{L}$ que foram secos sob $\mathrm{N}_{2}$, em seguida adicionado $1 \mu \mathrm{g}$ de ácido araquídico como padrão interno e 200uL de n-hexano, agitados em banho ultrassônico seguido pela injeção em cromatógrafo gasoso.

As condições cromatográficas foram: temperatura do injetor $250^{\circ} \mathrm{C}$, abertura da válvula de "splitless" 0,75 minuto, fluxo de limpeza do injetor $75 \mathrm{~mL} / \mathrm{minuto}$, temperatura do detector $300^{\circ} \mathrm{C}$, atenuação $16 \times 10^{11}$. Para a coluna a programação foi: $100^{\circ} \mathrm{C} / 2$ minutos, aumentando $50^{\circ} \mathrm{C} /$ minutos até $220^{\circ} \mathrm{C}$, permanecendo por 1 minuto, após aumentando $15^{\circ} \mathrm{C} /$ minutos até $235^{\circ} \mathrm{C}$, permanecendo 30 minutos.

\section{4 - Eficiência do método}

A performance do método pode ser verificada pela sua exatidão indicada pelos níveis de recuperação em cerveja contaminada artificialmente cujos valores médios foram de 83\% para DON e 103\% para T-2 (Tabela 4). A precisão do método adaptado, indicada pelo coeficiente de variação a partir de quatro determinações nos quatro níveis diferentes de contaminação artificial, como pode ser visualizado na Tabela 3, permitindo estimar repetibilidade de $2 \%$ e $4 \%$ para DON e toxina T-2, respectivamente. Estes resultados podem ser considerados satisfatórios, pois, se trata de quantificação de compostos traços, utilizando método envolvendo extração, sucessivas diluições e derivação [8].
TABELA 4. Recuperação de amostras artificialmente contaminadas.

\begin{tabular}{cccc}
\hline Toxinas & $\begin{array}{c}\text { Níveis de adição } \\
(\mathrm{ng} / \mathrm{mL})\end{array}$ & $\begin{array}{c}\text { \% de Recuperação } \\
\left(\text { média* }^{*}\right.\end{array}$ & $\begin{array}{c}\text { Repetibilidade } \\
(\text { CV\% })\end{array}$ \\
\hline \multirow{3}{*}{ DON } & 50 & 82,8 & \\
& 100 & 84,6 & 2 \\
& 150 & 83,0 & \\
\hline \multirow{3}{*}{ Toxina T-2 } & 200 & 81,5 & 4 \\
& 100 & 101,0 & \\
& 150 & 102,5 & \\
& 200 & 105,0 & \\
\hline
\end{tabular}

CV - Coeficiente de variação

Nas condições otimizadas do método, o limite de detecção e quantificação na amostra foi 21 e 60ng/mL para DON e toxina T-2 respectivamente, limites esperados quando se utiliza detector de ionização de chama.

As novas tendências para detecção de micotoxinas em bebidas apontam o emprego de colunas de imunoafinidade para extração e limpeza [23, 24, 32], mas esta técnica quando comparada com o método proposto tem como desvantagem o alto custo, a possibilidade de falsos positivos e a não detecção de várias toxinas simultaneamente.

\section{5 - Ocorrência de micotoxinas em cervejas dis- poniveis no comércio}

Para verificar a aplicabilidade do método adaptado foram coletadas 72 amostras compostas por lotes de 4 marcas e embalagens diferentes no comércio da cidade de Rio Grande. Durante a etapa de triagem, 6 amostras apresentaram suspeitas de contaminação por DON e 6 com toxina T-2. Tendo em vista a necessidade de confirmação foram usados para tais reações químicas e posterior derivação para cromatografia.

Para a confirmação da presença de DON foi empregada uma reação que propicia a redução do grupamento cetônico, transformando-o em álcool, o que ocasionou uma diminuição no tempo de retenção do derivado. A toxina T-2 derivada também apresentou uma diminuição no tempo de retenção quando empregadas as condições cromatográficas estabelecidas.

Foram confirmadas 4 amostras $(5,25 \%)$ contaminadas com a toxina desoxinivalenol, 3 amostras (4,45\%) com a toxina T-2 com 50 a 336ng/g e 114 a $249 \mathrm{ng} / \mathrm{g}$, respectivamente. Estas amostras não corresponderam ao mesmo lote, embalagem ou data de coleta.

Considerando-se que a média de consumo de cerveja per capita no Brasil é de 50L/pessoa/ano [33] um consumidor, poderia, no caso de ingerir estas amostras, contaminar-se com niveis superiores aos indicados como seguro à saúde humana [6]. Tal situação demonstra a necessidade de se avaliar a qualidade micotoxicológica dos insumos empregados na produção de cervejas e outras bebidas, bem como, a proposição de uma legislação 
específica para o produto acabado, o que seria mais facilmente monitorado com a disponibilidade de um método analítico confiável para realizar levantamentos nos produtos comerciais, a exemplo de outros de largo consumo.

\section{4 - CONCLUSÕES}

Os resultados deste trabalho indicaram que o método proposto é eficiente para detecção e quantificação de tricotecenos em cervejas, pois conforme seus indicadores de mérito apresentou uma recuperação média de 83 e $103 \%$ para DON e toxina T-2; precisão estimada pelo coeficiente de variação de 2 e $4 \%$ e limites de detecção na amostra de 21 e 60ng/mL, respectivamente.

O levantamento da ocorrência de tricotecenos em cervejas comercializadas no Rio Grande do Sul mostrou que 9,7\% das amostras coletadas estavam contaminadas com as toxinas pesquisadas, sendo 5,3\% com DON e $4,5 \%$ com toxina T-2. Os níveis detectados fo$\mathrm{ram} 50,123,154$ e $336 \mathrm{ng} / \mathrm{mL}$ e 114,208 e $249 \mathrm{ng} / \mathrm{mL}$ respectivamente, não sendo observada co-ocorrência.

\section{5 - REFERÊNCIAS BIBLIOGRÁFICAS}

[1] BADIALE-FURLONG, E. Tricotecenos em trigo: Um estudo de metodologia analítica, incidência, contaminação simultânea por outras micotoxinas e de alguns fatores que influem na produção no campo. Campinas, 1992. Tese (Doutor em Ciência de Alimentos) - Faculdade de Engenharia de Alimentos(UNICAMP).

[2] BADIALE-FURLONG, E.; SOARES, L.M.V. Gas chromatographic method for quantificationand confirmation of trichothecenes in wheat. Journal of the AOAC International, v. 78, n. 2, p. 386-390, 1995.

[3] BARAJ, E. Interferência dos tricotecenos no processo fermentativo. Rio Grande, 2000. Dissertação (Mestre em Engenharia de Alimentos) - Departamento de Química, Fundação Universidade Federal do Rio Grande (FURG).

[4] BENNET, G.A.; SHOTWELl, O.L. Criteria for determining purity of Fusarium mycotoxins. J. Assoc. Off. Anal. Chem., v. 73, n. 2, p. 270-275, 1990.

[5] CAULCUTT, R.; BODDY, R. Statistic for analytical Chemists. London, Chapman and Hall (ed.), 1983.

[6] FAO-CX/FAC 03/'35. Discussion paper on deoxynivalenol. Codex Committee on Food Additives and Contaminants, p. 1-12, 17-21, march, 2003.

[7] GILBERT, J.; STARTIN, J.R.; CREWS, C.; GILBERT, J. Optimization of conditions for the trimethilsilylation of trichothecene mycotoxins. Journal of Chromatography, v. 319, p. 376-381, 1984.

[8] HORWITZ, W.; KAMPS, L.R.; BOYER, K.W. Quality assurance in the analysis of foods for trace constituents. J. Assoc. Off. Anal. Chem., v. 63, p. 1344-1355, 1980.

[9] KIENTZ, C.E.; VERWEIJ, A. Trimethylsilylation and trifluoroacetylation of a number of trichothecenes followed by gas chromatographic analysis on fusedsilic capillary coluns. Journal of Chromatography, v. 355, p. 229-240, 1986.

[10] KIESSLING, K.H. Biochemical mechanism of action of mycotoxins. Pure and Applied Chemistry, v. 58, n. 2, p. $327-338,11086$.
[11] KOTAL, F.; HOLADOVÁ, K.; HAJLOVÁ, J.; POUSTKA, J.; RADOVÁ, Z. Determination of trichothecenes in cereal. Journal of Chromatography, v. 830, p. $2110-$ 225, 1101010 .

[12] LANGSETH, W.; RUNDBERGET, T. Instrumental methods for determination of nonmacrocyclic trichothecenes in cereals, foodstuffs and cultures. Journal of Chromatography A, v. 815, p. 103-121, 1998.

[13] MAROCHI, M.A. Uma metodologia para triagem, quantificação e confirmação de tricotecenos e zearalenona utilizando cromatografia de camada delgada. Tese de Mestrado em Ciência de Alimentos/FEA, Universidade Estadual de Campinas, 11088.

[14] NAKAJIMA, M. Mycotoxin Analysis for Federative republic of Brazil. Japão, 2001, 283 p. Training Course.

[15] NUNES, I.L. Micotoxinas, micoflora e seu potencial toxigênico em arroz destinado ao consumo humano. Rio Grande, 2001. Dissertação (Mestre em Engenharia de Alimentos) - Departamento de Química (FURG).

[16] OLIVEIRA, A.Q.; SOARES, L.M.V.; SAWAZAKI, E. Survey of deoxynivalenol, diacetoxyscirpenol, and T2 toxin in popcorn hybrids planted in the state of São Paulo and in popcorn commercialized in the city of Campinas, SP. Ciênc. Tecnol. Aliment., v. 21, n. 3, p. 330-333, 2001.

[17] RADOVÁ, Z.; HOLADOVÁ, K.; HAJLOVÁ, J. Comparison of two clean-up principles for determination of trichotecenes in grain extract. Journal of Chromatography, v. 829, p. 259-267, 1998.

[18] SCHOLLENBERGER, M.; LAUBER, U.; TERRY JARA, H.; SUCHY, S.; DROCHNER, W.; MÜLlER, H.-M. Determination of eight trichothecenes by chromatography - mass spectrometry after sample cleanup by a two-stage solid-phase extraction. Journal Chromatography A, v. 815, p. 123-132, 1998.

[19] SCOTT, P.M. Gas Chromatography of Mycotoxins. In: Chromatography of Mycotoxins: Techniques and Applications. Ed. V. Betina, Elsevier, Amsterdam.

[20] SCOTT, P.M. Assesment of Quantitative methods for determination of trichothecenes in grains products. Journal of the Association of Official Analytical Chemists, v. 65, n. 4, p. 876-883, 1982.

[21] SCOTT, P.M. Effects of Food Processing on Mycotoxins. Journal of Food Protection, v. 47, n. 6, p. 489-499, 1984.

[22] SCOTT, P.M. Gas chromatography of mycotoxins. Chromatography of Mycotoxins: Techniques and Applications. Ed. V. Betina, Elaevier, Amsterdam, 1991.

[23] SCOTT, P.M.; KANHERE, S.R.; DALEY, E.F.; FABER, J.M. Analysis of Canadian and imported beers for Fusarium mycotoxins by gas chromatography - mass spectrometry. Food Additives and Contaminants, v. 10, n. 4, p. 381-389, 1993.

[24] SCOTT, P.M.; KANHERE, S.R. Determination of ochratoxin $A$ in beer. Food Additives and Contaminants, v. 12, n. 4, p. 591-598, 1995.

[25] SCOTT, P. M. Mycotoxins transmitted into beer from contaminated grains during brewing. Journal of AOAC International, v. 79, n. 4, p. 875-882, 1996.

[26] SHEPHERD, M.J.; GILBERT, J. Long-term storage stability of deoxinivalenol standard reference solution. J. Agric. Food Chem., v. 36, p. 305-308, 1988.

[27] SNYDER, A.P. Qualitative, Quantitative and technological aspects of the trichothecene mycotoxins. 
Journal of Food Protection, v. 49, n. 7, p. 544-569, 1986.

[28] SOARES, L.M.V. Micotoxinas: Um método para análise simultânea e incidência em alimentos comercializados na região de Campinas. Campinas, 1987. Tese (Doutorado), FEA-UNICAMP;.

[29] TANAKA, T.; HASEGAWA, A.; YAMAMOTO, S.; SUGIURA, Y. Worlwide contamination of cereals by Fusarium mycotoxins nivalenol, deoxynivalenol andzearalenone. I Survey of 19 countries. J. Agric. and FoodChemistry, v. 36, n. 5, p. 979-983, 1988.

[30] TANAKA, T.; YONEDA, A.; INOUE, S.; SUGIURA, Y.; UENO, Y. Silmultaneous determination of trichothecene mycotoxins and zearalenone in cereals by chromatography - mass spectrometry. Journal of Chromatography, v. 882, p. 23-28, 2000.

[31] UENO, Y. Trichothecene mycotoxins. Mycologia, chemistry and toxicology. In H. H. Draper Ed., v. 3, p. 301-353, New York, 1980.

[32] Visconti, A.; PASCALA, M.; CEnTONZE, G. Determination of ochratoxin $A$ in domestic and importated beers in Italy by immunoaffinity clean-up and liquid chromatography. Journal of Chromatography A, v. 888, p. 321-326, 2000.

[33] Disponivel em: http://www.bevtech.com.br/cerveja/ merc_br.htm. Acesso em: 19/08/2003. 